\title{
Towards co-operative governance in the development and implementation of cross-sectoral policy: Water policy as an example
}

\author{
HM MacKay* and PJ Ashton \\ Division of Water, Environment \& Forestry Technology, CSIR, PO Box 395, Pretoria 0001, South Africa
}

\begin{abstract}
Water, because it is so fundamental and irreplaceable to humans and their activities, is an all-pervasive issue that underpins the social fabric of every society. This means that water policy is cross-sectoral, directly and indirectly affecting and affected by almost all other sectoral policies such as agriculture, urban development, rural development, health, housing, economic development. Effective implementation of any cross-sectoral policy requires that co-operative governance processes have to be established on the ground, and not just considered as some form of laudable principle. One of the most important steps in moving towards operational co-operative governance is the identification and agreement, by all the relevant and affected sectors, on shared primary objectives. This must be followed by the development of co-ordinated implementation programmes that can effectively achieve these objectives. In this paper, we explore a possible model for initiating co-operative governance processes in cross-sectoral policy implementation, using water as an example, and discuss some of the potential applications of this model.
\end{abstract}

Keywords: water policy, co-operative governance, integrated water resource management, South Africa

\section{Introduction}

This paper arose from discussions on how to make the implementation of national water policy as effective and efficient as possible, in the face of limited capacity and expertise, limited financial resources and above all, limited water resources. Different individuals involved in the development of national water policy and in the early phase of implementation felt that the process had been and remained extremely difficult, despite broad agreement about the importance of water in the national interest. When we asked the questions: "Why was it - why is it - so difficult?" and "Why does it feel that the effort needed to implement is so enormous?", two key reasons were suggested:

- Firstly, the natural resistance to change that characterises any change process, whether at the level of an individual, an organisation or a country, seemed to create a huge inertia in both the implementing agency (the Department of Water Affairs and Forestry (DWAF)) and the stakeholders (water users). There is a large body of knowledge, mostly contained in the business management literature, regarding the management of change processes and ways of overcoming this natural resistance and inertia. The relevance of this to water policy is discussed in MacKay et al. (2003). However, we felt that resistance to change, even to a major shift such as that represented by the 1997 water policy, did not sufficiently explain people's direct experiences of the policy development and implementation processes.

\footnotetext{
* To whom all correspondence should be addressed. Address for correspondence: Water Research Commission, Private Bag X03, Gezina, Pretoria 0031 , South Africa

푱 +2712 330 0340; fax: +2712 331 2565; e-mail: heatherm@wrc.org.za Received 3 July 2003; accepted in revised form 17 October 2003.
}

- Hence the second contributing factor: Water is a cross-sectoral issue, and water policy is thus by definition cross-sectoral policy that influences and affects all levels of society. This means that achievement of water policy goals requires collaboration, co-ordination and joint effort amongst the agencies responsible for other sectoral policies that affect or are affected by water. These include agriculture, housing, urban development, rural development, health, economic development and environment, as well as many others. The lead agent for water issues, in this case DWAF, may have to overcome the net inertia of all the other sectors as well as that within the water sector, a task which can seem overwhelming at times.

At some 'higher' level, all sectoral policies ultimately overlap and are interconnected, though there are some issues that are more strongly cross-sectoral than others, for example, environment, energy, water and poverty alleviation. Effective implementation of any cross-sectoral policy requires that co-operative governance processes have to be established on the ground, and not just considered as some form of laudable principle. In this paper, we explore a possible model for initiating co-operative governance processes in cross-sectoral policy implementation, using water as an example, and discuss some of the potential applications of this model.

\section{Background}

\section{Water in society}

Biologically, humans cannot survive without water. It is as essential as oxygen to the physiology of the human being. Because water is a life-or-death issue for humans, with direct physiological consequences as well as indirect effects on food production, actual or even potential water shortages lead to significant social stress as well as physiological stress in individuals and communities. Soci- 


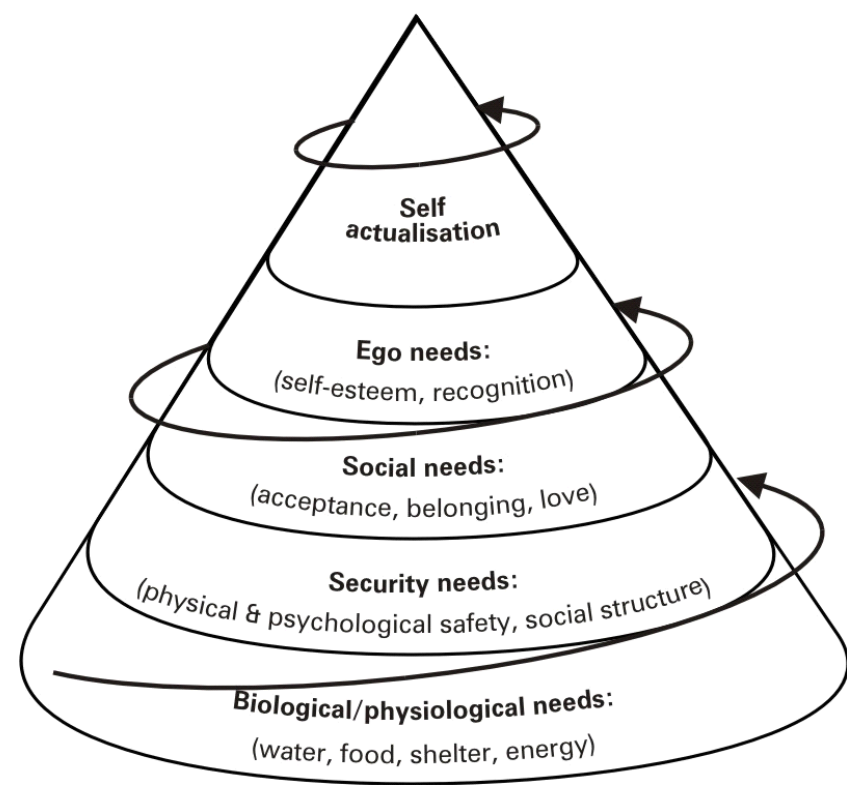

Figure 1

The Maslow hierarchy of needs (adapted and redrawn from Maslow, 1968), showing the spiral of progression that is followed in achieving these needs

eties develop various coping mechanisms for dealing with natural shortages of scarce resources such as land, water and grazing, but population pressures, large-scale degradation of natural resources and poor or inadequate governance systems limit the options available, particularly for those people dependent on subsistence livelihoods. There are already many local-scale conflicts in Africa which have their basis in growing competition for scarce natural resources (Lind, 2002), and it is likely that more conflicts will arise over water in future, especially in the face of climate change and desertification processes. Expanding populations and socio-economic development programmes place additional pressure on scarce resources throughout the continent. Policies related to development of natural resources should therefore take into account these linkages between biological stress on the resources and related social stress in the population dependent on these resources.

The psychologist Abraham Maslow developed a theoretical framework for the hierarchy of human needs, which placed essential physiological needs such as water, food and shelter at the bottom of the hierarchy as the basis or foundation of daily life (Maslow, 1968; Fig. 1). Once their basic physiological needs have been met, humans will then attempt to meet higher needs for physical security, then social needs and then the individual need for self-actualisation, in order to achieve their full potential. When the most basic 'lower' needs are not met, people tend to remain 'trapped' in those 'lower' levels and cannot develop further.

Since people's daily activities all focus on meeting their needs in some way, at whatever level of the hierarchy that may be relevant, much human endeavour goes towards securing their basic physiological needs. For a huge number of people in Africa, meeting the most basic needs for food and water in a situation of poor economic and infrastructural development is a task that requires all of their available attention and energy. For example, some 109.6 million (54.4\%) of the 201.5 million residents of the 12 mainland Southern African Development Community (SADC) states lack access to an improved water source (Ashton, 2003). Of the 109.6 million people lacking access to improved water supplies, approximately
$21.9 \%$ (24 million) are urban residents whilst the remainder (78.1\%; 85.6 million) live in more remote rural areas (Ashton, 2003).

Thus water, because it is so fundamental and irreplaceable to humans and their activities, is an all-pervasive issue that underpins the social fabric of every society, particularly in African countries. This means that water policy directly and indirectly affects, and is affected by, almost all other sectoral policies such as agriculture, urban development, rural development, health, housing and economic development. Making a change in the water sector has 'ripple'effects throughout society. Hence, making a change in how water is perceived, valued and managed requires that the whole of society, as represented by all the other sectors, comes along with and fully supports the change, not just the agency or Government department that is responsible for managing water resources. Change on this scale, across multiple sectors and at multiple levels of society, represents a very significant challenge.

\section{The cycle of development}

In accordance with the gradual progression of people or societies through the Maslow hierarchy, development goals tend to change as people's expectations change. Once needs are met at the most basic level, people's expectations of what their needs are also change. Expectations usually increase because people now enjoy a new ('higher') level of development and have 'new' perspectives of their most pressing and basic needs. For example, meeting people's most basic requirements for water, food and shelter should lead to improved quality of life and more diversity in daily activities that are higher up on the Maslow hierarchy, as more energy is freed up from pursuing the lowest level of needs. This can raise expectations of what constitutes "basic" water supply and sanitation, which, in turn, may require additional expenditures for the development of infrastructure and services to meet these expectations. Thus development tends to be an episodic or continuous cyclical process, rather than a goal that is achieved once and then maintained at that level for a prolonged period of time (Fig. 2; Ashton, 2003). Accordingly, upward movement through the Maslow hierarchy tends also to be a cyclical or spiral process (Fig. 1). Clearly, these issues have important implications for all attempts to ensure sustainable development in Southern Africa: medium- and long-term development goals must be re-examined regularly to ensure that some harmony is reached between the achievement of goals and the changing expectations of people.

It is quite normal for the population of a country to have groups or communities who are seen to be at different levels of the development spiral at any one time. In South Africa, some 6.4 million people (14.\% of the population) still lack access to an improved water source whilst approximately 17.3 million people ( $37 \%$ of the population) have no access to an appropriate sanitation system (DWAF, 2003). In addition, their supplies of food are often insecure, being very dependent on erratic natural rainfall patterns and climatic conditions. Yet, simultaneously, some sectors of the population are relatively high up on the spiral, enjoying conditions equivalent to those in the first world and pursuing needs which are near the top of the Maslow hierarchy. This situation is reflected in South Africa's relatively high Gini index of 59.3, which is comparable to many other developing countries, as can be seen in Table 1 (UNDP, 2003). The Gini index measures the extent to which the distribution of income (or consumption) among households within a country deviates from a perfectly equal distribution. A value of 0 represents perfect equality, while a value of 100 represents perfect inequality. 


\begin{tabular}{|l|l|}
\hline \multicolumn{2}{|c|}{ TABLE 1 } \\
$\begin{array}{c}\text { Gini indices of several } \\
\text { developed and developing } \\
\text { countries, including South } \\
\text { Africa (UNDP, 2003) }\end{array}$ \\
\hline Country & Gini Index \\
\hline Japan & 24.9 \\
Sweden & 25.0 \\
United States & 40.8 \\
India & 37.8 \\
Uganda & 37.4 \\
Kenya & 44.5 \\
Nigeria & 50.6 \\
Botswana & 63.0 \\
Nicaragua & 60.3 \\
Uruguay & 44.8 \\
South Africa & 59.3 \\
\hline
\end{tabular}

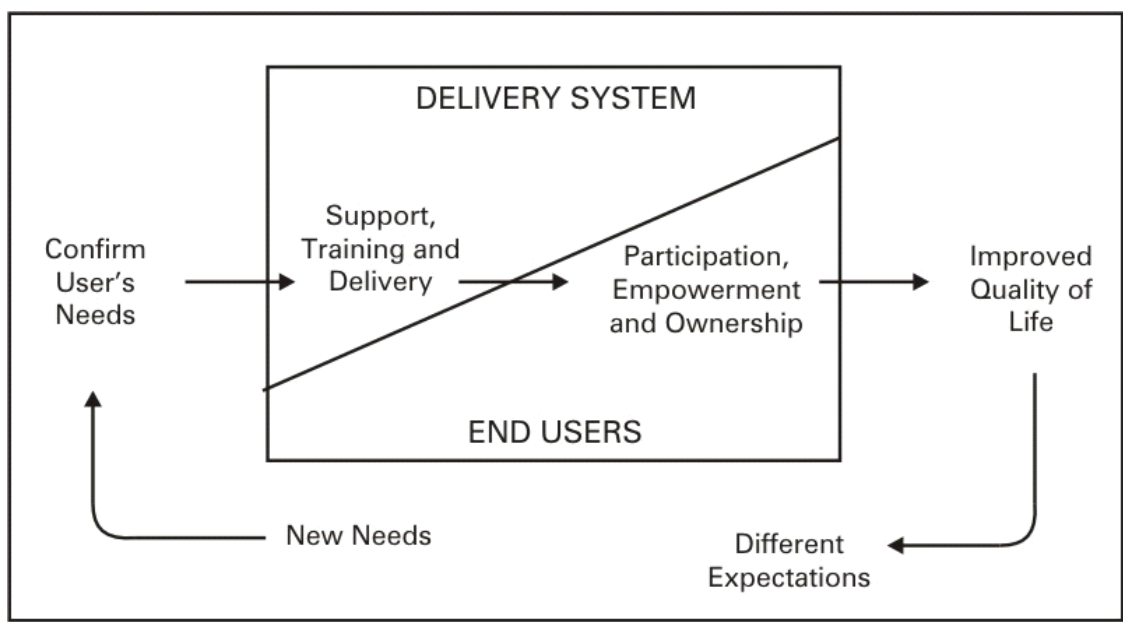

Figure 2

Schematic diagram showing the typical cyclical sets of changes that occur during the process of 'development', as the needs of individuals and communities are met. The partnership between service delivery agents and the final end users of these services promotes a strong sense of empowerment and ownership of the 'final product', and recipients are now able to articulate new sets of needs that must be satisfied (redrawn from Ashton, 2003).

National policy is seldom able to address equally the needs of all sectors of the population: Local development goals that are appropriate or customised to local conditions, must be established within the framework of national policy. It is at the local level where the possibilities appear to be greatest for conflicts or disputes between policy sectors.

\section{Difficulties in development and implementation of cross-sectoral policy}

\section{Conflicting sectoral priorities}

One of the common problems with cross-sectoral issues such as water is that of conflicting priorities in the different sectors that have an effect on, or are affected or influenced by, water. Government agencies may often unknowingly work in direct opposition to each other due to a lack of high-level co-ordination and agreement on shared priorities. Such conflicts can arise through misinterpretation or misunderstanding of policy and legislation, as much as from the actual intent of policy and legislation. A good example would be the situation where agricultural extension officers advise people to clear riparian vegetation for planting subsistence crops, and thereby increase their yields on fertile riparian soils, while the water management agency simultaneously requires that riparian zones be strictly protected in order to prevent bank erosion, sedimentation of river channels and increased suspended sediment loads in water, which degrade water resource quality and increase water treatment costs (GWP, 2000). Both agencies are acting according to their official mandates but they are in direct opposition to each other on the specific issue. The end result is likely to be a lack of concerted action on either front due to confusion, and the people who most need to benefit from increased subsistence crop yields and from protection of water resources, will probably experience neither of these benefits.

\section{Vertical boundaries between sectors}

Since 1994, the South African Government has been engaged in an intense series of complex, participative processes to renew, revital- ise and reform the policy and legislative basis of Government, to eliminate past inequities and to ensure that all citizens enjoy equal access to basic human rights. These principles and sentiments are eloquently captured in the country's Constitution, which represents the 'highest' legal instrument in the country. At the level of the national Constitution, the fundamental principles of equity, sustainability and guaranteed human rights that underlie the country's policies and laws are clearly aligned amongst the different sectors. These principles provide broad guidance for each of the relevant Government departments to draw up sector-specific policies and laws within its area of mandate. Arising from this process, for example, we have the National Water Policy (DWAF, 1997), the National Water Act (Republic of South Africa, 1998a), the National Environmental Management Act (Republic of South Africa, 1998b), and many more.

The complex process of sectoral reform is still in progress; whilst some key sectors (e.g. water) have recently completed substantial reforms of policy and legislation, others have yet to finalise this process. At the level of national Government, the new principles, policies and legislative instruments in each sector appear to be aligned closely with, and fully support, the key principles embodied in the Constitution (Fig. 3). However, the clear separation of line functions between different Government departments (e.g. water, agriculture, housing, etc.) makes it difficult to attain proper levels of alignment and coherence between these different functions, as each department operates independently within its area of mandate. The core vision encapsulated in the Constitution becomes more "fuzzy" as the level of implementation is moved outwards from principles through policy, legislation and regulation to the lowest levels of governance, making co-operation and alignment across sectors at the lower (local) levels that much more difficult.

Therefore, whilst the principles and policies derived from the Constitution are to a large extent complementary or supportive, there are several instances where specific legislative or regulatory components are at worst contradictory or, at best, do not complement each other. In some cases, such as issues associated with mining activities, there is also a lack of clarity as to which statutory requirements take precedence, or are more important, than others. 


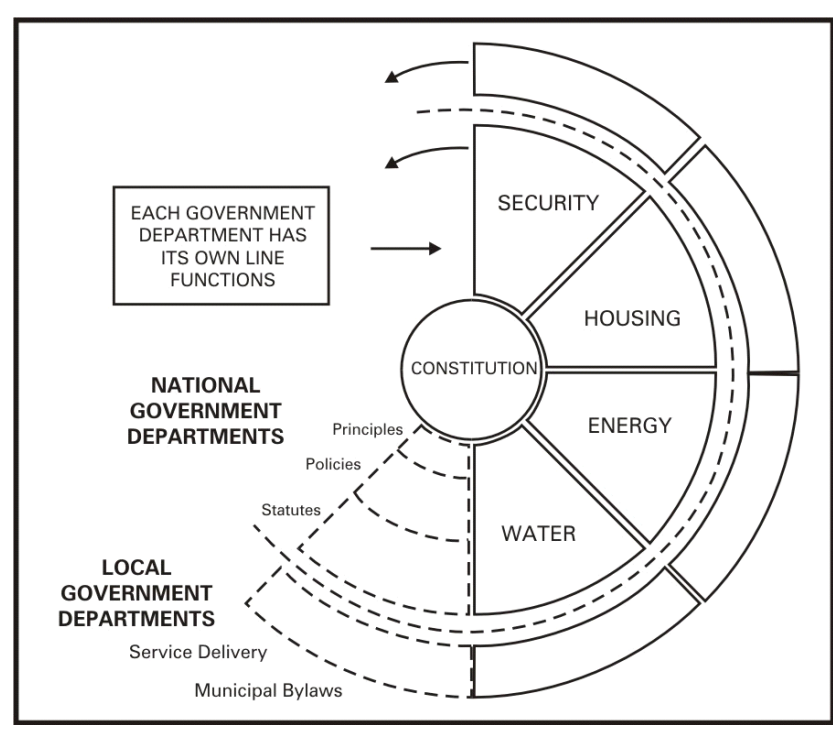

Figure 3

Conceptual diagram showing the relationships between the national Constitution, functions of national-level line departments and local Government. The separate identity and functions of each line department complicate alignment of national policy and statutes with service delivery processes.

This causes confusion amongst stakeholders and officials alike and hampers decision-making on some key development issues. While this situation has been made significantly more challenging due to the dramatic political and administrative changes in South Africa since 1994, which require re-alignment of previous functions and powers as well as development of new functions and powers, the problems also derive from a strong history of colonialism, in which certain sectors were accorded primacy over others.

\section{Poor alignment between national and local levels}

At the level of local Government, where the key functions of service delivery have been devolved to the lowest feasible or practicable level, there is even greater difficulty in ensuring proper alignment and coherence between national and local levels, as well as between different sectors. At local level, the situation is particularly complicated by the need for some measure of additional geographical alignment or integration between local authorities, for example the different towns located along a river system or contained within a water management area (WMA). This problem is in part also caused by the difficulties experienced in 'translating' shared, but often non-quantifiable (or un-quantified), principles and policy elements into operational-level delivery of specific services.

Wide geographical disparities in resource availability (e.g. water, arable land) are another reason for some of the difficulties experienced in aligning national visions, principles, policies and statutes for a specific resource such as water, with local-level responsibility for service delivery and resource management. The need to meet growing demands for reliable supplies of wholesome water has resulted in different Government departments and local authorities having to make calculated 'trade-offs' or exchanges. For example, the decision to provide domestic water supplies to informal settlements without supplementing these with appropriate sanitation or refuse removal services often leads to increased contamination of local water supplies and thus increased human health risks. At local level, it is critically important to ensure wide participation in, and transparency of, decision-making processes so that the potential beneficiaries or recipients fully understand the sequences and limitations of service delivery constraints. In turn, this helps them to understand their own levels of responsibility and accountability for the operation, maintenance or payment for any services received.

\section{Sequence of service delivery}

The importance of understanding the sequence or timing of service delivery components at local level is closely related to the urgent need to meet the basic human needs of households and larger communities. At local level, the different needs embodied in the lowest Maslow hierarchy level (Fig. 1) are seldom prioritised and agreed upon with the beneficiaries before the delivery process is started. The nature of these basic needs (usually food, water and shelter) is often so pressing that there is seldom time to build shared awareness or understanding of the reasons why they cannot be delivered or realised immediately. In addition, if only one need (out of a possible suite of different needs) is met at a particular point in time, an unsustainable situation can easily be created. For example, if water is provided to a poor rural community located on land with low agricultural potential and where the community has little or no prior experience in economic activities, the community may become artificially stabilised by the provision of water in an area where the existing natural resources may not be able to support food and shelter needs. These other needs would then have to be met by additional resources imported from outside the area, often subsidised by some other sector of the population. In such an example, both the beneficiaries and the subsidising population are likely to express their dissatisfaction with/to the responsible local or national authorities.

The need to 'bridge' these gaps in the national-to-local, and inter-sectoral, alignment of principles, policies and statutes is already acute. Further delays in achieving this alignment are likely to lead to greater public dissatisfaction and the risk of increased polarisation in public opinion. Ultimately, this may hamper the effectiveness and efficiency of service delivery and delay fulfilment of society's needs.

\section{Possible model for cross-sectoral policy development and implementation}

\section{The child protection policy model}

Like water, most issues that are at the lower end of the Maslow hierarchy of needs tend to be underpinning in society and thus cross-sectoral in nature. Protection of children from neglect and abuse, whether physical or psychological, is similarly a critical element of the social fabric and, because it is right at the foundation of the hierarchy of needs, it requires co-ordinated responses from across several sectors. Without intervention, the cycle of abuse and violence leads a society into a vicious downward spiral, with a probable ending (at least where children are concerned) that is likely to be similar to the recent or current situations in Sierra Leone and Liberia.

There is national policy for protection of children in South Africa; it is cross-sectoral policy because appropriate interventions must be made by each relevant sector of Government, including justice, policing, education and social development/welfare. The lead agent for implementation is the Minister for Safety and Security. However, interventions must be integrated across all sectors to ensure the full and effective protection of children. The 
Figure 4

Model of South Africa's child protection policy framework, showing interventions at different levels and in multiple sectors, aimed at eradicating the three priority "crimes against society" (CSIR, 2002)

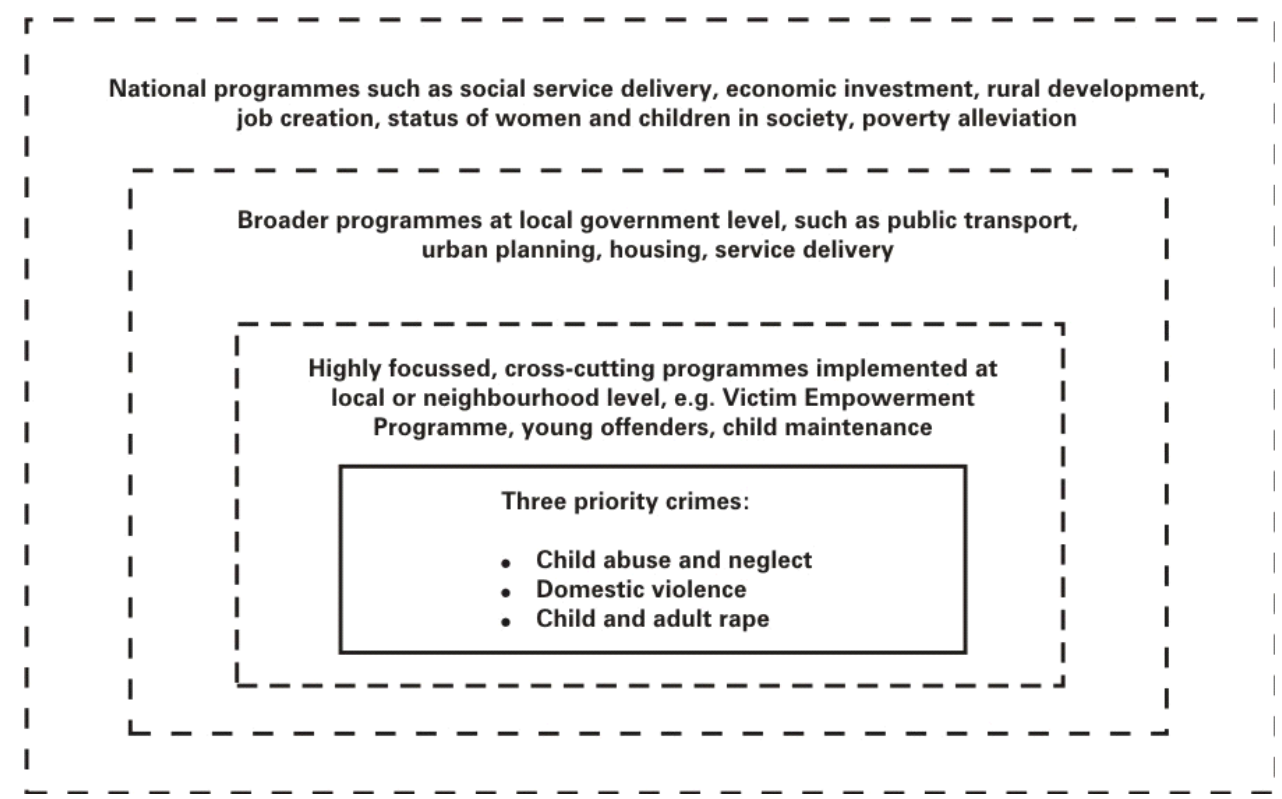

structure of the child protection policy model (CSIR, 2002) serves as a possible model or 'template' for dealing with water issues, and is discussed here in the context of implementation of generic crosssectoral policy.

In South Africa, violence against children is recognised as one element of a larger societal cycle, the pathology of which is reasonably well understood. If the cycle is to be broken, then the protection of children must be addressed in all of the stages and places in which children live and grow. Hence, the policy is that children should be protected in their homes, in their neighbourhoods, in their schools, in public places, in the transport system, in the judicial system and in the health system. Clearly, this requires that efforts be initiated within several different sectors, including education, social development, housing, justice, policing, and at several different levels, from the level of societal values to on-theground operations.

In developing the child protection policy, attention was first focused on the three priority crimes that are seen as crimes against society, and which are at the heart of the cycle of abuse and violence against children, namely: child abuse and neglect; domestic violence; child and adult rape. These three are inter-connected in the abuse/violence cycle, and in this respect it is impossible (and inappropriate) to separate women's issues from children's issues. Secondly, without confining the debate to a single sector such as justice, policing, education or welfare, the policy developers considered all the preventive and reactive interventions that would be required from the various sections of Government and levels of society in order to make a real and tangible difference in the current situation (Fig. 4). These interventions included highly-focused core programmes that could be initiated at local or neighbourhood level and maintained from within a single agency; broader multisectoral programmes at local Government level; and national programmes that address behavioural and attitude changes in the wider society.

The model in Fig. 4 was based on analysis and understanding of the cause-effect relationships that underpin the cycle of violence against children, and how the abuse of children affects society as a whole, for the express purpose of identifying each policy sector that would affect, or be affected by, the country's child protection policy. This approach enables policy changes in the lead sector
(Safety and Security) to be matched by appropriate policy shifts in all the other relevant sectors and, in theory, helps to ensure harmonisation of policies and procedures across all agencies dealing with child abuse. If all the other sectors share the same vision and fulfil their mandate of working towards a common goal, implementation should be much more effective and efficient. In this way, progress would also not rely on a single department or group to lead the whole national effort (an almost impossible task with the inertia that is inherent in each Government department).

There is growing awareness that South Africa's child protection policy is not being effectively implemented, despite having been developed several years ago. There are several possible reasons for this lack of effective implementation, some of which could also be applied as lessons for water policy. These include:

- Insufficient or incomplete communication of the vision to all the sectors involved has led to insufficient harmonisation and co-operation at the operational levels. This has resulted in things still being done very much as they have always been done - along narrow sectoral lines and often with one or more sectors in direct conflict.

- Several key pieces of national legislation have been reformed, and others are in draft form, but the entire suite of necessary national legislation has not yet been promulgated. Thus, again, the way in which things are done on the ground has not changed sufficiently to have a noticeable effect on society, despite some successes in certain areas, such as the provision of special children's courts and sexual offences courts in a few magisterial districts.

- The capacity to implement the policy at local or operational levels is often insufficient or, sometimes, totally absent. However, this is a problem which has been cited in relation to almost every single piece of national policy to date, and perhaps South Africa should critically examine the perceived gap between our ideals, as represented by the suite of new policies that have been developed since 1994, and the apparent lack of capacity to implement these policies. There may be a need to prioritise better in order to utilise available expertise, capacity and resources most effectively.

- The responsibility for implementation has been retained largely 


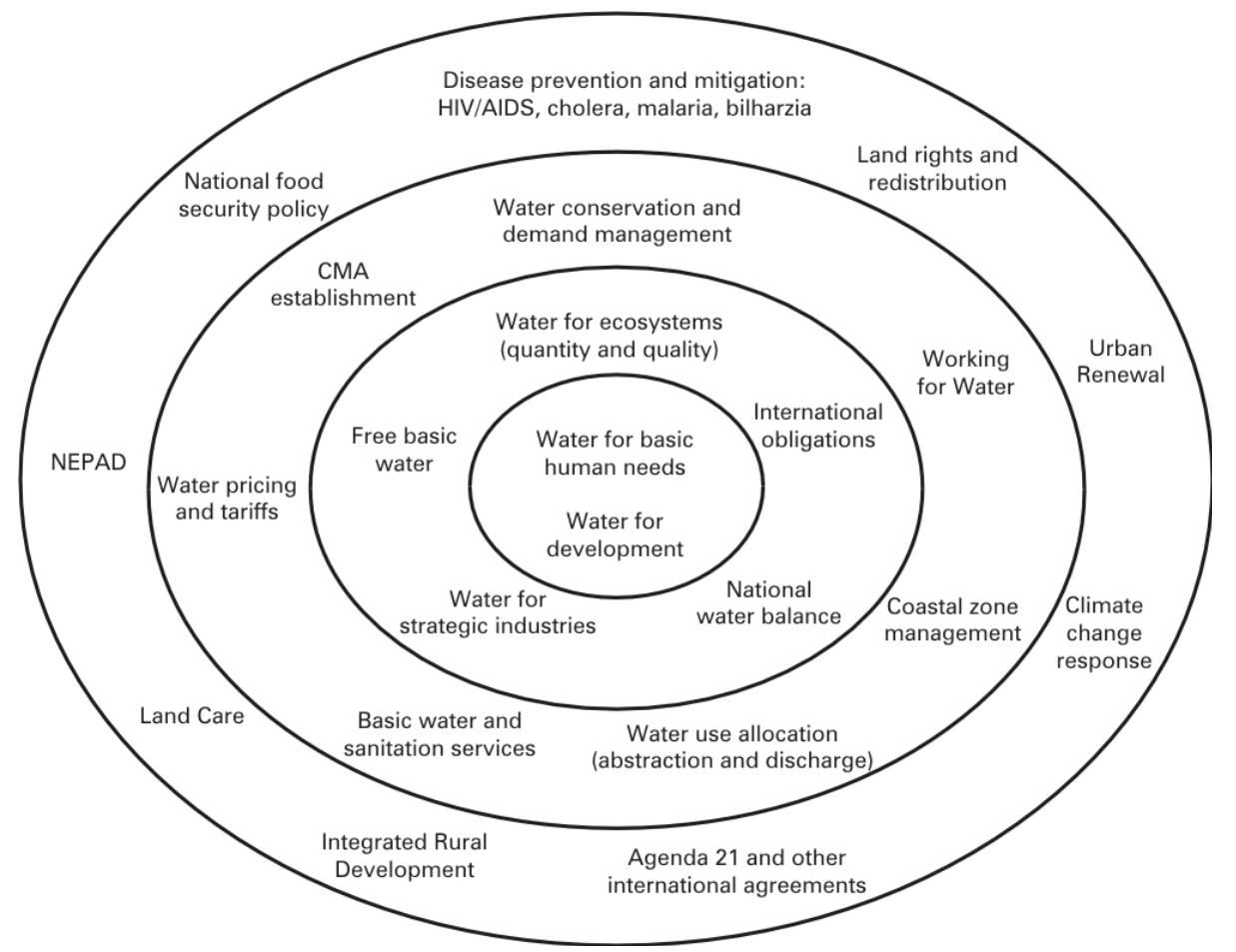

Figure 5

Proposed framework for water policy implementation across all related sectors, showing examples at each "level". The framework consists of two core priorities, supported by: an inner ring of highly focused programmes implemented and maintained by the lead agent, DWAF; a second ring of waterfocused programmes which are implemented by other agencies at local levels; an outer ring of broader societal programmes that affect or are affected by water policy implementation, and that contribute to the longterm success of water policy implementation.

in the hands of national Government. Until all three sectors of society, i.e. Government, the NGO community and civil society, are able to work together in a shared policy framework, with joint responsibility and according to agreed priorities, the capacity for implementation is likely to remain insufficient.

\section{Generic elements of the child protection policy}

Despite the problems experienced with its implementation, the child protection policy model still offers a very useful conceptual framework for development and implementation of cross-sectoral policies, such as those dealing with water. The generic elements of the model are:

- The need for stakeholders in all related sectors to identify and reach agreement on what the key priority issues are, preferably those as low on the Maslow hierarchy as is relevant to the issue under review

- At a strategic level, and based on a shared understanding of how each of the priority issues affect society, identify and clarify or confirm all the necessary types of interventions at societal, Government and local level

- Identify and confirm the responsibilities and lead agents for actions related to the programme of interventions

- Explicitly communicate the vision and programme of interventions to all responsible and related sectors, particularly at operational levels; make additional allowance for those stakeholders who may enter the process part-way through

- At local level, draw up an explicit sequence of co-ordinated implementation activities and clearly defined responsibilities for these activities according to the agreed priorities, preferably in the order in which those priorities appear as needs on the Maslow hierarchy.

\section{Potential benefits of such a model}

By making the core vision fully explicit in all interventions and actions at operational level, transparency is promoted in the process of stepping down from principles to policy to legislation to regulation to action. Actions on the ground by elements of all sectors become, and are openly seen to be, consistent with the core vision and can be related easily to the vision's principles. This in turn promotes transparency and is likely to engender wider support for both the policy and the implementation process from stakeholders and other affected parties.

When used in the policy development phase, such a model promotes greater efficiency at all levels: Capacity across all related sectors is mobilised and aligned with a shared vision and sectoral policy and legislation can be harmonised as necessary in a proactive, structured way, rather than reactively in a piecemeal fashion. While there will always need to be a single lead agent, the energy and capacity of that lead agent can be greatly enhanced by the shared energy of other aligned sectors.

\section{A water policy model}

During the development of the 1997 water policy, there was much discussion about possible relationships or connections with other sectoral policies, including agricultural policy, rural and urban development and economic policy. However, although the linkages and inter-relationships were fairly well understood, a model in the form similar to that of the child protection policy was never made explicit. If that had been done, perhaps the alignment and harmonisation of related sectoral policy and legislation could have been promoted more proactively, making implementation of the water policy much more efficient. South Africa's water policy implementation is still in its very early stages, so perhaps there is still merit in developing the model retrospectively, identifying gaps that may be critical to later successful implementation and identifying those key areas where improved co-operation between different sectoral agencies could create synergy.

The vision that guided the 1997 National Water Policy can be summed up in the remarkably concise and eloquent slogan that was adopted by DWAF at the time: "some for all forever". This slogan 
represents a firm commitment to ensure that the benefits of water and of water use will be equitably shared in perpetuity amongst all the people of our country, without prejudice to future generations, i.e. sustainably. All people are guaranteed the right to have their basic needs met (currently defined in regulation as $25 \ell$ of wholesome water per person per day or $6 \mathrm{k} \ell$ per household per month within $200 \mathrm{~m}$ of the dwelling place (Republic of South Africa, 1997)). Beyond that amount, water will be allocated according to the principles of beneficial, economically efficient and environmentally sustainable use. The central ideal is that we should utilise water resources in order first to ensure that one of the very lowest needs on the Maslow hierarchy is met for all people, and secondly to promote social and economic development.

In developing a framework for cross-sectoral implementation of water policy, we might identify the core priority issues (Fig. 5) as:

- Water for basic human needs

- Water for development.

Of interest to note here is that water for ecosystems, which is given special status through the ecological component of the Reserve, is not necessarily one of the core priorities or goals to be achieved. Rather, it is an enabling intervention: Only if aquatic ecosystems are protected through the provision of sufficient water of an appropriate quality to protect ecosystem structure and function, can the sustainability of water resources be assured. So "water for ecosystems" might be one of the highly focused programmes in the "inner ring" of interventions in Fig. 5. The lead agent for implementation of these focused programmes would be DWAF, and in most cases DWAF would actually undertake the implementation process and retain overall responsibility and accountability for progress achieved in respect of these programmes.

Other "inner ring" programmes are:

- Ensuring that sufficient water is available to meet international obligations in shared river basins

- Allocation and provision of reliable water supplies for certain strategic industries such as power generation

- Ensuring that water is made available for the free basic water initiative, which extends to rural as well as urban communities

- Responsibility for the national water balance, i.e. long-term planning for the reconciliation of water supply and demand at national level, including water resources development projects, inter-basin transfers and bulk allocations of water at the level of Water Management Areas (WMAs). This should inform economic and infrastructural policy and strategy throughout South Africa.

The "second ring" in Fig. 5 comprises programmes that focus on water, which may be initiated by a central lead agent, but are implemented and maintained in other sectors at provincial, local or WMA level. These include, in no particular order of importance:

- Water pricing and tariffs, which are specific to WMAs, though these must be determined within the framework of the national water pricing strategy

- Water conservation and demand management programmes, which are area-specific as well as sector-specific, but which contribute to the overall priorities of making enough water available to meet everyone's basic needs and freeing up appropriate quantities of additional water for economic development

- The Water Education Programme, a schools programme that is run in conjunction with the Department of Education, which aims to change people's perceptions about the value of water - The Working for Water Programme, which has multiple objectives of improving water availability, providing jobs and conserving biodiversity

- Provision of RDP-level water and sanitation services by local authorities, which is a critical component of poverty alleviation initiatives

- Coastal zone management, particularly estuaries, whose biological productivity within estuarine and marine environments depends on the provision of sufficient freshwater inflow from upstream

- Allocation of authorisations for water uses (abstraction, discharge and other Section 21 water uses) under the National Water Act of 1998, which will be carried out at Catchment Management Agency (CMA) level within the policy and regulatory frameworks provided by DWAF as the lead agent

- The establishment of CMAs in each of the 19 WMAs in the country, which, by devolving decision-making authority to the lowest possible level, should ensure improved equity in access to water and incorporation of local level economic, social and environmental imperatives into water resource management.

The "outer ring" in Fig. 5 consists of broad national programmes that may be led by other sectors, but where water plays a significant role in affecting priorities and implementation. Here, inter-linkages with water policy will be bi-directional, in that water policy priorities may be affected by the setting of priorities within these external programmes, or else policy decisions made in the water sector may affect the successful implementation of these programmes. A few of these are briefly described below.

- The National Land Care Programme is a national initiative whose local programmes are aimed at improving the condition and management of land, which will also benefit the protection of water resource quality and, in turn, will contribute to sustainable catchment management if the objectives are aligned with water resource management priorities.

- The national policy on food security and self-sufficiency in food affects agricultural priorities and hence water allocation priorities for irrigation farming.

- South Africa needs a concerted response to climate change across all affected sectors; should this evolve as national policy, then water policy will undoubtedly be affected, especially in terms of water resource development projects, and also through water allocation and water conservation priorities.

- The Integrated Rural Development and Urban Renewal Programmes are dependent upon, amongst other things, the provision of basic water and sanitation for their success.

- The country's land reform and redistribution initiative should be closely linked to water policy, since the sustainability of land reform programmes, particularly on irrigable land, depends on how and under which financial conditions water is provided to small farmers. In areas with marginal soils, the provision of water alone may not be sufficient to ensure sustainability, and the water may be more beneficially used elsewhere or for other, more beneficial purposes. The land and water sectors need to develop an integrated approach at national, provincial and local levels to planning and supporting effective land reform.

\section{Applications and further development of the model}

The generic framework, as represented by the examples in Figs. 4 and 5 , has potentially wider application in other cross-sectoral 
policy issues where co-operative governance and alignment are needed within and between sectors, as is typical of the environment sector. The National Environmental Management Act (NEMA) is currently being revised, and this could provide an opportunity to identify where and what specific reviews may be needed of other sectoral policy and legislation in order to support the objectives of the NEMA.

Another obvious potential application of the framework is in developing a shared vision and management plan for a WMA. The 19 WMAs in South Africa are large as well as geographically, socially and economically diverse and the CMAs will need to integrate local water priorities with WMA priorities, and sometimes with international priorities, especially where their river systems are shared with neighbouring countries (SADC, 2001; Ashton, 2003).

The model may also be useful in establishing a management plan for a transboundary water resource, where some focused programmes are the responsibility of the international river basin organisation once it has been established, some are the responsibility of local authorities in basin states, and some are national programmes of the basin states. There may even be a need for a fourth ring for shared river basins, to encompass programmes and initiatives at the regional level such as the Southern African Development Community (SADC).

There is potential for such a model to be used to support the process of developing shared regional or Africa-wide objectives such as those related to the New Partnership for Africa's

Development (NEPAD, 2001), along with action plans and supporting programmes that are implemented at national or subregional level but are complementary and co-operative.

Recommendations for further work include:

- Discussion of the proposed model in Fig. 5 with more people in the water sector, identification of any gaps and refinement of the model

- An analysis of policy, legislation and regulation, strategy and programme objectives for all the initiatives included in the refined water policy model, to identify where and at what level alignment and harmonisation between and within sectors is needed, and what forms these should take, in order to meet the core objectives of the water policy

- Explore other policy issues or arenas that are to enter a policy review process, where this concept could provide a logical framework for evaluation and implementation.

\section{Conclusion}

Successful long-term implementation of water policy has always been constrained by insufficient capacity in terms of trained personnel, infrastructure, financial resources and equipment; this situation will undoubtedly continue in future. Nevertheless, there is significant potential for synergy to be created by promoting closer alignment and harmonisation of policy and legislation across all sectors that affect, or are influenced by, water policy, in order to provide more impetus for change. Co-operative govern- ance needs to be moved beyond principles into reality if South Africa's urgent development imperatives are to be met within a realistic time-frame. The model provided by the child protection policy, and developed here for water policy, could serve as a suitable template for generating a shared vision and a suite of sectoral and integrated interventions that would more strongly support water policy implementation.

\section{Acknowledgements}

The Water Research Commission is thanked for funding part of the preparatory work for this paper. The initial development of the thinking behind this paper was supported through a post-doctoral fellowship awarded to Heather MacKay by the Centre for Water in the Environment, University of the Witwatersrand. The constructive comments of the anonymous reviewers of the initial draft added much value to the paper.

\section{References}

ASHTON PJ (2003) Water and development: a southern African perspective. In: Slack P and Trottier J (eds.) The Twelfth Annual Linacre Lectures - 2002. Oxford University Press, Oxford. (In press).

CSIR (2002) Proc. Child Abuse Workshop. January 2002. Crime Prevention Research Centre, CSIR, Pretoria.

DWAF (1997) White Paper on a National Water Policy. Department of Water Affairs and Forestry, Pretoria.

DWAF (2003) Annual Report 2002/2003. Department of Water Affairs and Forestry, Pretoria.

GWP (2000) A Vision of Water for Food and Rural Development, The Hague: Global Water Partnership. $65 \mathrm{pp}$.

LIND J (2002) Towards innovative conflict prevention and management strategies. Report of the Consultative Session and Regional Conference on the Ecological Sources of Conflict in Sub-Saharan Africa. Eco-Conflicts 2(1) May 2002. African Centre for Technology Studies, Nairobi.

MACKAY HM, ROGERS KH and ROUX DJ (2003) Implementing the South African water policy: Holding the vision while exploring an uncharted mountain. Water SA 29 (4) 353-358.

MASLOW AH (1968) Toward a Psychology of Being. Van Nostrand Reinhold, London. 214pp.

NEPAD (2001) The New Partnership for Africa's Development (NEPAD), Document of Accord drawn up on 3 July 2001, 60 pages, available at: http://www.nepad.org.

REPUBLIC OF SOUTH AFRICA (1997) Water Services Act (Act No 108 of 1997). Department of Water Affairs and Forestry, Pretoria.

REPUBLIC OF SOUTH AFRICA (1998a) National Water Act (Act No 36 of 1998). Department of Water Affairs and Forestry, Pretoria.

REPUBLIC OF SOUTH AFRICA (1998b) National Environmental Management Act (Act No 107 of 1998). Department of Environmental Affairs and Tourism, Pretoria.

SADC (2001) Revised Protocol on Shared Watercourse Systems in the Southern African Development Community (SADC) Region. Windhoek: Southern African Development Community, available at: www.sadc.int.

UNDP (2003) Human Development Report 2003. Millennium Development Goals: A Compact Among Nations to End Human Poverty. United Nations Development Programme. 